\title{
A esfera pública e as proteções legais anti-racismo no Brasil*
}

\author{
Felipe Gonçalves Silva \\ Professor da Faculdade de Direito de São Bernardo do \\ Campo e pesquisador do Cebrap \\ Marta Rodriguez de Assis Machado \\ Professora da Escola de Direito de São Paulo da \\ Fundação Getúlio Vargas e pesquisadora do Cebrap \\ RúRION MELO \\ Professor da Universidade Federal de São Paulo e \\ pesquisador do Cebrap
}

* A versão aqui apresentada reproduz de forma resumida e levemente modificada nosso artigo publicado em Machado, M. R. A.; Melo, R.; Silva, F. G. "The public sphere and the anti-racism legal protections in Brazil". In: Collection of Scientific Papers 2009. Riga: RSU, 2010, p. 302-11. O artigo reúne algumas das principais ideias presentes numa pesquisa-piloto mais ampla sobre Esfera Pública e Democracia, iniciada em 2005 e coordenada pelo Professor Sérgio Costa (Freie Universität, Berlim) no Núcleo Direito e Democracia do CEBRAP. Gostaríamos de agradecer a todos os membros do Núcleo Direito e Democracia envolvidos nas sucessivas discussões acerca deste projeto, especialmente a Marcos Nobre, José Rodrigo Rodriguez, Carolina Cutrupi, Flávia Püschel, Fabíola Fanti e Marina Ganzarolli. Os dados empíricos colhidos até o momento estão expostos de maneira mais detalhada em Machado, M. "A legislação anti-racismo no Brasil e sua aplicação: um caso de insensibilidade do Judiciário?”. In: Revista Brasileira de Ciências Criminais, n. ${ }^{\text {74 }}$. Em Werle, D. et al. "Para além da inefetividade da lei? Estado de direito, esfera pública e anti-racismo". In: Lavalle, A. (org.) O Horizonte da Politica: questóes emergentes e agendas de pesquisa. São Paulo: Cosac \& Naify (no prelo), discutimos as relações entre o processo de juridificação, os debates na esfera pública e a democracia. Para uma discussão mais detida dos dados à luz da questão da interpretação e indeterminação do Direito, ver Machado, M.; Püschel, F.; Rodriguez, J. R.. "The Juridification of Social Demands and the Application of Statutes: An Analysis of the Legal Treatment of Anti-Racism Social Demands in Brazil”. In: FORDHAM Law Review, vol. 77, 2009. 
Resumo: O artigo parte do pressuposto teórico-analítico de que uma melhor compreensão da efetividade do Estado de direito em democracias constitucionais depende da análise e da reconstrução dos vínculos internos entre Estado de direito, a dinâmica da esfera pública e a própria democracia. A tematização e as controvérsias públicas sobre os problemas que já são ou que deveriam ser regulados pelas leis existentes podem colocar em ação processos judiciais que visam uma configuração mais concreta do sistema de direitos vigente. Recorrer a tais premissas teóricas implica ir além do mero diagnóstico do (Não)-Estado de direito nos países da América Latina e no Brasil em particular. Nossa hipótese - fundada inicialmente na teoria crítica da sociedade tal como foi formulada por Jürgen Habermas, principalmente em seu conceito de esfera pública - levou-nos a observar o que realmente estava ocorrendo na relação entre sociedade civil e o Estado e a investigar se o aumento da discussão sobre problemas raciais na esfera pública, assim como a crescente organização do movimento negro, produziu nos últimos anos algumas transformações nas instituições jurídicas.

Palavras-chave: esfera pública, Estado de direito, Jürgen Habermas, medidas anti-racismo
AвSTRACт: This paper starts from the analytical theoretical presupposition that a better understanding of the issue of the effectiveness of rule of law in constitutional democracies depends on the analysis and reconstruction of the internal connections between rule of law, the dynamics of the public sphere, and democracy itself. The thematization and public controversies over problems that already are or should already be regulated by the existing laws can trigger judicial processes that envisage the more concrete configuration of the prevailing system of rights. Taking recourse to this analytical theoretical premise implies going beyond mere diagnosis of non-rule of law in Latin American countries in general and in Brazil in particular. Our hypothesis -grounded initially on the critical theory of society formulated by Jürgen Habermas, particularly on his concept of public sphere - asked us to see what is really happening in the relationship between civil society and state, and then try to see if the growth of discussion about racial problems in the public sphere, as well as the increase of organization of the black movement, produced in the last years some changes in the legal institutions.

KeYwORDs: public sphere, rule of law, Jürgen Habermas, anti-racism measures

\section{Introdução}

Nas últimas décadas, muitos estudos procuraram compreender e descrever o contexto racial brasileiro em diferentes esferas 
sociais, culturais e institucionais. A conclusão geral de tais estudos é que o Brasil lida há séculos com problemas que impedem o desenvolvimento de uma genuína cidadania democrática entre indivíduos livres e iguais, a saber, o racismo, a discriminação e o preconceito que formam conjuntamente uma barreira à democracia, tanto de um ponto de vista institucional (em termos de acesso à justiça e tratamento igual, dificuldades de participação na esfera pública e impossibilidade de gozar dos direitos assegurados formalmente pela lei), quanto de uma perspectiva sócio-econômica. Os muitos estudos desenvolvidos em diferentes âmbitos nacionais mostraram que o racismo impede a livre mobilidade social e o avanço de minorias étnicas ou raciais.

A evidência empírica reunida nesses estudos contradiz as teses agora consideradas vulgares de que o Brasil ostenta uma "democracia racial". Na verdade, a tese da democracia racial começou a ser questionada já na década de 1950 nos trabalhos da Escola de Sociologia de São Paulo (Florestan Fernandes, Octavio Ianni, Fernando Henrique Cardoso, entre outros), mas foi na década de 1980 que estudos conduzidos por instituições governamentais e por organizações da sociedade civil começaram a desmascarar a existência do racismo na sociedade brasileira, e a trazer de uma vez por todas para o topo da agenda política as questões raciais relacionadas aos temas da discriminação e do preconceito. A partir de então, as denúncias de racismo na sociedade brasileira passaram a se dirigir cada vez mais ao Estado democrático de direito, o qual, segundo suas pretensões normativas de assegurar a liberdade e a igualdade entre seus cidadãos, é obrigado a assumir uma postura positiva no combate à discriminação racial. Em suma, o desmascaramento do mito de uma "democracia racial" nos levou a uma problematização cada vez mais intensa da "efetividade" da democracia no Brasil.

Uma grande parte da literatura sobre a efetividade das democracias latino-americanas sublinha uma carência do Estado de direito que se expressaria claramente na discrepância entre a letra da lei existente e as normas que efetivamente governam a interação social. O diagnóstico da (in)efetividade do rule of law ou do Estado de direito nos países da América Latina tem sido um dos 
aspectos mais valorizados, com uma boa dose de razão, no debate sobre os sentidos da democracia e dos processos de democratização nesses países. Segundo esse diagnóstico, diante da ineficácia do princípio da lei, da incompletude do Estado, especialmente em sua dimensão legal, e da violação recorrente de muitos dos direitos fundamentais que compõem o núcleo universalista da concepção de cidadania moderna, pode-se questionar o caráter "democrático" da maioria dos países da região. ${ }^{1}$ Contudo, pode-se argumentar que muitas dessas abordagens falham ao tentar evitar as armadilhas daquilo que no Brasil ficou conhecido como "a sociologia da ausência". A partir dessa perspectiva, o real funcionamento da democracia é descrito em termos do que o falta, ou seja, de sua incompletude em relação ao ideal normativo da democracia ou ao Estado democrático de direito abstratamente definido. Tal diagnóstico, entretanto, repetido de forma homogênea para casos e demandas variantes, afasta-nos de uma compreensão mais atenta dos avanços e entraves envolvidos em processos democráticos historicamente observados.

Procuramos questionar a maneira como o diagnóstico da "inefetividade" é construído lançando mão de premissas teóricas diferentes. Tendo como pano de fundo as considerações sobre a política e o direito tal como aparecem desenvolvidas principalmente na teoria crítica apresentada por Jürgen Habermas, partimos do pressuposto teórico-analítico de que, para uma melhor compreensão acerca da efetividade ou não-efetividade do rule of law nas democracias constitucionais, é necessário analisar e reconstruir os vínculos internos entre legitimidade do Estado de direito, dinâmica da esfera pública e cidadania democrática. ${ }^{2}$ Trata-

1. Cf. Méndez, J.; O’Donnell, G.; Pinheiro, P. S. (org). Democracia, violência e injustiça: O Não-Estado de direito na América Latina. São Paulo: Paz e Terra, 2000.

2. Cf. Habermas, J. Faktizität und Geltung. Frankfurt/M: Suhrkamp, 1998. Ver também Costa, S. As cores de Ercilia: Esfera pública, democracia, configurações pós-nacionais. Belo Horizonte: UFMG, 2002; Benhabib, S. "Sobre um modelo deliberativo de legitimidade democrática”. In: Melo, R.; Werle, D. L. (org). Democracia deliberativa. São Paulo: Esfera Pública, 2007, p. 47-80; e Günther, K. "Qual conceito de pessoa de que necessita a teoria do discurso 
se de compreender a dinâmica dos debates e conflitos na esfera pública, nos quais transcorrem os processos de formação política da opinião e da vontade, não apenas como fonte da legitimação das decisões políticas e da legislação vigente, mas também como componente fundamental para provocar uma configuração ou implementação mais concreta da legislação já existente. ${ }^{3}$ Essa segunda dimensão dos processos democráticos acontece na medida em que ocorre na esfera pública a tematização e problematização de questões de interesse público que já são matéria de regulação legal. O pressuposto mais geral é o de que existe um vinculo estreito entre a dinâmica da esfera pública e o Estado democrático de direito, tanto do ponto de vista da legitimação quanto das condições de efetividade da lei. A tematização e as controvérsias públicas em torno de problemas que já são ou deveriam ser regulados pelas leis existentes - e que acabam por levantar questões sobre a própria autocompreensão política dos cidadãos - podem provocar processos judiciais que visam a dar uma configuração mais concreta ao sistema de direitos, impondo a vigência do direito e diminuindo o hiato existente entre normas jurídicas e práticas sociais.

Ao lançarmos mão de premissas teórico-analíticas centradas nas relações entre Estado de direito, dinâmica da esfera pública e a consolidação da cidadania democrática, poderemos ir além do mero diagnóstico do (Não)-Estado de direito nos países da América Latina em geral e no Brasil em particular. Para justificar essa hipótese teórica mais geral sobre como funcionam as democracias latino-americanas, escolhemos uma controvérsia específica a ser acessada empiricamente: as relações raciais. Racismo e discri-

do direito? Reflexões sobre a conexão entre pessoa deliberativa, cidadão e pessoa de direito”. In: Machado, M. R. A.; Püschel, F. P. (org). Teoria da responsabilidade no Estado democrático de direito: Textos de Klaus Günther. São Paulo: Saraiva, 2009, p. 27-52.

3. Cf. Peters, B. "Recht, Staat und politische Öffentlichkeiten als Formen sozialer Selbstorganisation”. In: Peters, B. Der Sinn Von Öffentlichkeit. Frankfurt/M: Suhrkamp, 2007, p. 31-54. Ver também Costa, S.; Melo, R.; Silva, F. G. "Sociedad civil, Estado y derecho en América Latina: tres modelos interpretativos". In: Araújo, K. (org). ¿ Se acata pero no se cumple? Estudios sobre las normas en América Latina. Santiago: LOM, 2009, p. 199-222. 
minação racial não representam apenas questões importantes para uma teoria crítica da democracia, mas são problemas urgentes a serem enfrentados no Brasil.

\section{O conceito de esfera pública}

O conteúdo normativo de um conceito de democracia voltado à formação de normas não está limitado aos arranjos institucionais de um Estado democrático de direito. Um dos aspectos mais ricos da teoria crítica de Jürgen Habermas no campo das teorias da democracia consistiu em sublinhar os elementos radicalmente democráticos dos processos políticos de formação da opinião e da vontade que ocorrem para além dos processos institucionais de comunicação e tomadas de decisão. A formação institucionalizada da opinião e da vontade retira sua legitimidade das comunicações políticas permeáveis a diversos tópicos, valores, contribuições e argumentos que circulam de forma porosa na esfera pública. É evidente que a própria formação da opinião - concebida, desde Kant, com base no "uso público da razão" ${ }^{4}$ - deve ser assegurada legalmente como exercício pleno da liberdade política de cidadãos livres e iguais. Porém, embora institucionalizada, tal formação da opinião não se encontra e nem pode ser formalmente organizada em seu conjunto. Em seu livro Facticidade e validade, Habermas reconstruiu como acordos políticos pretensamente legítimos dependem das relações entre uma formação política da opinião legalmente organizada e os fluxos espontâneos de uma comunicação livre. Além disso, Habermas ofereceu uma interpretação da "soberania popular" constituída por processos de comunicação pública que demandavam formas de soberania "sem sujeito", analisando a formação da opinião na circulação de poder que perpassavam associações civis. A legitimidade de um Estado democrático de di-

4. Cf. O'Neill, O. Constructions of reason: Explorations of Kant's practical philosophy. Cambridge University Press, 1989; Bohman, J. Public deliberation. Cambridge: MIT Press, 2000; Rawls, J. "A idéia de razão pública revisitada". In: Melo, R.; Werle, D. L. (org). Democracia deliberativa, p. 145-92; e Melo, $\mathrm{R}$. "O uso público da razão como procedimento: Um contraste entre Rawls e Habermas”. In: doispontos, 5, 2008, p. 113-41. 
reito encontra-se assim atrelada às fronteiras entre sociedade civil e Estado, exigindo, por um lado, a expansão da liberdade e igualdade sociais entre os cidadãos e, por outro lado, a democratização das instituições do Estado. Não pode haver, portanto, Estado de direito legítimo sem "democracia radical". ${ }^{5} \mathrm{O}$ modelo habermasiano de uma política deliberativa ligada à formação da opinião na esfera pública nos permitiu avançar nas pesquisas que envolviam a relação entre direito e democracia no Brasil e enriquecer um diagnóstico alternativo sobre o (Não)-Estado de direito.

Nossa investigação tenta dar início a uma compreensão da "efetividade" da legislação que seja sensível à dinâmica reflexiva dos processos de criação e aplicação do direito. Nesse sentido, como dito acima, a abordagem aqui apresentada se diferencia dos diagnósticos obtidos pela mera contraposição entre as normas que compõem o Estado de direito e as práticas institucionais existentes. A partir das controvérsias públicas informais (mídia, associações e movimentos da sociedade civil) e formais (as deliberações e decisões justificadas nos espaços de deliberação especializados do complexo institucional parlamentar e jurídico) em torno das questões do racismo, da discriminação e do preconceito, o que analisamos foi como a tematização pública destas questões pode ou não ativar uma certa "dialética" existente - e inerente ao próprio Estado democrático de direito - entre igualdade formal e desigualdade factual. ${ }^{6}$ Esse objetivo investigativo nos levou a uma compreensão da "efetividade" do direito que não se limita à análise das decisões finais no âmbito da aplicação da lei pelo judiciário; ou seja, em nosso caso, não pretendemos avaliar a "efetividade" da legislação anti-racismo apenas, ou mesmo prioritariamente, em relação ao número de condenações constatadas, mas antes a partir da gênese, descritivamente mais rica e dinâmica, das relações políticas entre sociedade civil e Estado na esfera pública.

A esfera pública não pode ser entendida como uma instituição, nem como um sistema ou uma organização: ela se caracteriza

5. Cf. Habermas, J. Faktizität und Geltung, p. 13.

6. Cf. Idem, p. 493 e ss. 
por um fluxo comunicacional de horizontes abertos, permeáveis e deslocáveis, adequada para a comunicação de conteúdos, opiniões e tomadas de posição; nela os fluxos comunicacionais são filtrados e sintetizados, a ponto de se condensarem em opiniões públicas enfeixadas em temas específicos, fornecendo razões para fundamentação de decisões que atingem toda a coletividade. A infraestrutura social da esfera pública consiste em um leque abrangente de atores que contribuem com a formação da opinião, os quais, em seus diferentes formatos (tais como associações, sindicatos, instituições culturais, grupos de interesse, igrejas e instituições de caridade), abarcam demandas e temas diversificados. ${ }^{7}$

A esfera pública é descrita por Habermas como uma caixa de ressonância para problemas que devem ser trabalhados pelo sistema político e pelo judiciário. Nesse sentido, forma um sistema de alarme com sensores não especializados, porém sensíveis no âmbito de toda sociedade. À função de sinalização deve ser acrescentada a de uma problematização eficiente, isto é, na medida em que os problemas são tratados na esfera pública com a intensidade e dramaticidade requeridas, os âmbitos competentes para a resolução de tais problemas podem ser sensibilizados e mobilizados. Além disso, a capacidade limitada dos sistemas político e jurídico de tratar dos problemas sociais em toda sua complexidade precisa ser compensada por um controle social posterior de suas rotinas de funcionamento. A esfera pública tem o papel de fazer com que o complexo formado pelo parlamento, pela administração pública e pelo judiciário consolide, em seus modos de operação, "contextos de justificação" que estejam ligados aos "contextos de descoberta" dos problemas e conflitos concretos vividos pelos cidadãos.

Quando a legitimação democrática é analisada nesses termos, conseguimos ter uma imagem complexa das relações entre cultura, política e direito como um todo. A infraestrutura normativa do Estado constitucional democrático é representada em termos de canais, filtros e transformadores de vários fluxos comunicativos. Esses fluxos circulam entre as redes informais da esfera pública,

7. Cf. Idem, capítulo VIII. 
por um lado, e as legislaturas, tribunais e órgãos do judiciário e da administração pública em geral, por outro. Em cada uma dessas dimensões operam padrões de tematização e deliberação próprios. ${ }^{8}$ Nesse sentido, o "espaço de razões" admissíveis nas diferentes dimensões da esfera pública pode ser mais formalizado e vinculante (como no caso do espaço de deliberação especializado do judiciário), ou mais aberto e inclusivo (como na esfera pública cultural informal). E à medida que os fluxos comunicativos conseguem ultrapassar certas comportas institucionais (decisões legislativas, judiciais e administrativas), ocorre uma mudança tanto no modo de comunicação quanto no impacto regulatório: a influência pública é transformada em poder comunicativo, o poder comunicativo em competência jurídica ou poder administrativo, e ambos na execução de decisões judiciais ou na implementação de programas e políticas públicas. ${ }^{9}$

\section{A esfera pública anti-racismo nos processos de criação e aplicação da lei}

As mobilizações públicas de combate ao racismo contam já há algumas décadas com uma forte representação no Brasil. No entanto, muitas interpretações apontam para a incapacidade de tais mobilizações gerarem efeitos significativos no interior do Estado de direito. Parece existir uma "naturalização" do sistema jurídico em seu conjunto como estruturas não apenas institucionalmente intransponíveis às lutas sociais contra a discriminação racial, mas como culturalmente reprodutoras das desigualdades e preconceitos existentes. Esse diagnóstico fechado, porém, não permite abarcar a complexidade dos processos envolvidos nas lutas pela criação e aplicação do direito, impedindo sobretudo uma identificação mais precisa dos obstáculos que a elas se impõem. Nossa hipótese - que não reflete imediatamente o ponto de vista do movimento social, embora compartilhe sua desconfiança quanto ao estado da

8. Sobre “tematização", ver Costa, S. As cores de Ercília, capítulo 1.

9. Idem,ibidem. Para o modelo de circulação do poder utilizado por Habermas, ver também Peters, B. Die Integration moderner Gesellschaften. Frankfurt/M: Suhrkamp, 1993, parte 3. 
questão racial - nos impeliu a analisar esse diagnóstico negativo e entender o que poderia realmente estar acontecendo na circulação de poder entre Estado e sociedade civil. Mais precisamente, procuramos investigar se o aumento de tematização e discussão sobre problemas raciais na esfera pública, bem como uma crescente organização do movimento negro no Brasil, produziu nos últimos anos algumas modificações nas instituições jurídicas.

No contexto dos processos de tematização pública do racismo, que vão desde a politização das diferenças culturais até a transnacionalização e pluralização do anti-racismo, passando pelas conquistas do movimento negro brasileiro em termos de políticas públicas, é possível observar que as deliberações efetivadas na esfera pública informal provocaram modificações significativas na produção legislativa brasileira, principalmente no que se refere à criminalização de práticas racistas, embora seja notável, mais recentemente, a tendência de deslocar o tratamento jurídico do tema, saindo do mero âmbito penal.

A influência da esfera pública sobre a legislação foi certamente bastante paulatina. As primeiras demandas públicas por uma legislação penal anti-racismo são manifestadas a partir de 1945, após o fim da ditadura Vargas. ${ }^{10}$ A reabertura política ali iniciada deu vazão a "diversas manifestações de democracia"11, as quais permitiram o reestabelecimento da imprensa negra e o ressurgimento de "organizações livres de negros", destinadas à articulação de reivindicações políticas, econômicas e culturais do movimento - como, por exemplo, a revista Senzala e os jornais Alvorada, Niger, Novo Horizonte, Novo Mundo e A Tribuna Negra, bem como as organizações União dos Homens de Cor (UHC), Associação do Negro Brasileiro (ANB) e Teatro Experimental do Negro (TEN). Sob organização do Teatro Experimental do Negro, foram realizadas em São Paulo e no Rio de Janeiro as duas edições da Convenção

10. Cf. Fullin, C. S. "Direito e racismo: Observações sobre o alcance da legislação penal antidiscriminatória no Brasil”. In: Revista da Faculdade de São Bernardo do Campo. 2000, Vol. 6, p. 21.

11. Cf. Silva, J. "A união dos homens de cor: Aspectos do movimento negro dos anos 40 e 50". In: Estudos Afro-Asiáticos, 2003, 25, p. 215-35. 
Nacional do Negro Brasileiro (1945 e 1946), tendo como resultado das deliberações ali empreendidas a elaboração do Manifesto à Nação Brasileira, cujas reivindicações incluíam as exigências inéditas de "inserir a discriminação racial na Constituição como crime de lesa-pátria" e de "uma lei anti-discriminatória, acompanhada de medidas concretas para impedir que esta constituísse somente uma proclamação jurídica, vazia de sentido". ${ }^{12}$

O Manifesto à Nação Brasileira foi enviado a todos os partidos políticos envolvidos nos preparativos da Assembléia Constituinte de 1946, tendo recebido o apoio da União Democrática Nacional, do Partido Social Democrático e do Partido Comunista. Entretanto, suas reivindicações por institutos jurídicos de combate à discriminação racial apenas foram incorporados na Constituição de 1946 com a cláusula geral de que "todos são iguais perante a lei" e com a proibição de propagandas que veiculem preconceitos de raça: "Não será tolerada propaganda de guerra, de processos violentos para subverter a ordem pública e social, ou de preconceitos de raça ou de classe" (CF1946, art. 141, § 50). ${ }^{13}$ A demanda por uma legislação nacional que punisse as práticas de racismo, reivindicada no Manifesto, foi incorporada pelo ordenamento jurídico brasileiro apenas em 1951. A Lei 1.390/51, conhecida como "Lei Afonso Arinos", tipificou como contravençôes penais (i.e. infrações consideradas de menor gravidade que os crimes, apenadas com prisão simples e multa), condutas relativas à "recusa, negação de atendimento ou acesso de pessoas a estabelecimentos públicos ou privados, por preconceito de cor ou raça". $\mathrm{Na}$ época, essa lei sofreu uma série de críticas e resistências, sendo acusada de constituir uma afronta à "democracia racial" brasileira e encontrando grandes dificuldades em sua aplicação. Posteriormente, outras leis passaram a tratar do assunto, como é o caso dos preceitos que vedavam várias formas de difusão de campanhas ou pronuncia-

12. Fullin, C. S. "Direito e racismo: Observações sobre o alcance da legislação penal antidiscriminatória no Brasil". In: Revista da Faculdade de São Bernardo do Campo, Vol. 6, p. 21.

13. Cf. Idem, p. 22. 
mentos discriminatórios (por meio de comunicação, propaganda eleitoral, pronunciamentos oficiais etc.)

Em 1980, foi realizada na Câmara Municipal de São Paulo a 2a Semana da Cultura Negra, com a incumbência de avaliar a eficácia da legislação anti-racismo vigente e de elaborar o anteprojeto de uma nova legislação de combate à discriminação racial. Como ponto de partida dos debates ali transcorridos, figurava um certo consenso sobre a inadequação e inefetividade da Lei Afonso Arinos, o principal estatuto legal vigente de combate à discriminação. Entre as principais causas para a ausência de condenações derivadas da referida lei, foi apontado, em primeiro lugar, o excesso de "casuísmo" na redação de seus artigos: o tipo penal ali criado era excessivamente detalhista em relação às ações que configuravam a conduta discriminatória. ${ }^{14}$ Devido a uma determinação muito específica dos casos em que deveria se aplicar a referida lei, os quais não abarcavam a maior parte das situações discriminatórias, a lei Afonso Arinos acabaria por cair em desuso pela dificuldade de se enquadrar as práticas concretas de discriminação ao tipo penal por ela criado. Outro defeito ali apontado era a pequena gravidade do tratamento jurídico configurado pela lei, visto que, como dito acima, ela tratava a discriminação racial não como crime, mas sim como mera contravenção penal.

As articulações para a modificação do tratamento jurídico da questão racial brasileira se refazem com os preparativos para a nova Assembléia Constituinte. Em 1986 foi realizada, em Brasília, a Convenção "O Negro e a Constituinte", destinada à elaboração e formalização das reivindicações de vários setores do movimento negro a serem direcionadas à nova ordem constitucional nascente. As demandas resultantes desta convenção - entre elas, a de tornar o racismo um "crime inafiançável e imprescritível" - foram entregues, em abril 1987, ao presidente da Comissão da Ordem Social, responsável por encaminhá-las à Comissão de Sistematização que, por sua vez, elaboraria o texto a ser votado pelo Plenário da

14. Cf. Prudente, E. Preconceito racial e igualdade jurídica no Brasil. Campinas: Julex, 1989. 
Assembléia Nacional Constituinte. ${ }^{15}$ A demanda por uma maior gravidade da política punitiva de combate ao racismo, reivindicada no legislativo nacional desde 1980, foi enfim incorporada na Constituição Federal de 1988, em seu artigo 5o, inciso XLII: "a prática do racismo constitui crime inafiançável e imprescritível, sujeito à pena de reclusão, nos termos da lei”.

A legislação infraconstitucional de combate ao racismo se consolida com a Lei n. ${ }^{\circ}$ 7.716/89 (Lei Caó), a qual regulamentou o referido art. $5^{\circ}$, XLII da Constituição de 88 , descrevendo propriamente as condutas que passariam a configurar o "crime de racismo". De modo geral, nota-se que as condutas típicas, agora definidas como crimes inafiançáveis e imprescritiveis, englobam as anteriormente tratadas como contravenções pela Lei Afonso Arinos, descritas de forma mais detalhada, mas também abrangem um maior número de situações. As penas previstas passaram a ser bem mais elevadas - passaram a ser de reclusão em todos os casos, com cominações de penas mínima e máxima em abstrato variando de 1 a 3 anos, para a previsão mais baixa, e 2 a 5 anos, para a previsão mais grave.

Essa lei sofreu algumas modificações em seu texto, como é o caso, por exemplo, da introdução do artigo 20, pela Lei n. ${ }^{\circ}$ 8.081/90, que tipificou como crime a prática, incitação ou indução de atos discriminatórios ou de preconceito de raça, cor, religião, etnia ou procedência nacional pelos meios de comunicação ou por publicação. E da Lei n. ${ }^{\circ}$ 8.882/94, que acrescenta um parágrafo a esse artigo para tratar do crime de fabricação, comercialização, distribuição ou veiculação de símbolos, emblemas, ornamentos, distintivos ou propaganda que utilizem a cruz suástica ou gamada, para fins de divulgação do nazismo. Essas mudanças, entretanto, não interferiram nos problemas acima apontados.

Em 1997, outra alteração legislativa teve lugar em resposta às críticas de "ineficácia” na aplicação da lei. Antes dessa lei, apon-

15. Fullin, C. S. "Direito e racismo: Observações sobre o alcance da legislação penal antidiscriminatória no Brasil". In: Revista da Faculdade de São Bernardo do Campo, Vol. 6, p. 14. 
tava-se que ofensas que continham elementos racistas eram freqüentemente classificadas como injúria simples pelos Tribunais, o que era criticado especialmente por ter uma pena baixa (1 a 6 meses ou multa) e por desprezar o elemento racial da conduta, enxergando-a exclusivamente como uma ofensa à honra individual. A fim de corrigir esse conflito sobre a aplicação de normas, a alteração legislativa da Lei no 9.459/1997 criou o tipo de injúria racial, como uma forma qualificada de injúria. A pena prevista em abstrato para essa conduta é significativamente mais grave, aumentou para 1 a 3 anos de reclusão e multa, tendo esse agravamento por fundamento justamente o elemento racial.

A análise do desenvolvimento da legislação nacional anti-racimo mostra-nos, pois, dois elementos fundamentais à nossa investigação: a constituição de uma esfera pública destinada à avaliação e crítica das inovações jurídicas relativas ao combate do racismo e a capacidade das instituições legislativas nacionais incorporarem, em alguma medida, as contribuições por ela produzidas. A nossa hipótese é a de que as deliberações públicas de tematização e combate ao racismo na esfera pública informal têm conseguido penetrar no sistema legislativo brasileiro de maneira progressiva. Embora não tenhamos ainda investigado a adequação dos canais de participação da sociedade civil no processo legislativo, dos mecanismos representativos e dos processos institucionais de tramitação dos projetos de lei, é possível desde já verificar que muitas das demandas formuladas pelos movimentos anti-racistas alcançaram os debates legislativos e, em algumas oportunidades, como visto, resultaram na criação e modificação de institutos jurídicos no direito positivo brasileiro. Seria precoce assumir um diagnóstico ampliado sobre a efetividade das instituições democráticas envolvidas na criação da legislação brasileira anti-racismo, mas de qualquer modo podemos já observar que ela não se apresenta como resultado da mera auto-programação de uma instituição política estanque, mas mostra-se sensível aos resultados de deliberações públicas produzidas na sociedade civil.

Entretanto, no que diz respeito à aplicação dessa legislação pelos Tribunais, o sentimento mais comum tanto por parte de atores do movimento social como por parte de juristas parece ainda 
decorrer de uma interpretação negativa dos supostos avanços da legislação. Nesse campo, encontramos, em sua maioria, críticas que apontam que a legislação anti-racista seria "pouco eficaz" ou que ela "não encontrou a aplicação que se esperava junto ao Poder Judiciário $^{16}$, uma vez que há poucos casos de condenação criminal. ${ }^{17}$ No que diz respeito ao Judiciário, menciona-se frequentemente que juízes, brancos em sua grande maioria, seriam insensíveis ao problema racial da sociedade brasileira ou poderiam estar adotando eles mesmos posturas consideradas racistas. ${ }^{18} \mathrm{Tal}$ pesquisa está ainda em andamento, razão pela qual ainda não pretendemos fornecer, neste texto, uma resposta mais abrangente a essa questão. Gostaríamos, contudo, de tecer algumas considerações a partir de resultados parciais da pesquisa, que por ora referem-se apenas ao Tribunal de Justiça do Estado de São Paulo. ${ }^{19}$

Ao analisar os 111 julgados proferidos por esta corte entre 1998 e 2007, verificamos em primeiro lugar que apenas 45 do total dos casos chegaram ao Tribunal após a prolação de sentença de mérito (condenatória ou absolutória) em primeira instância, o que seria o fluxo natural dos casos no Judiciário. Observamos, assim, uma tendência a se questionar o prosseguimento dos casos antes de seu término em primeira instância.

16. Cf. Abreu, I. B. "O racismo e a jurisprudência do Egrégio Tribunal de Justiça do Estado de São Paulo”. In: Penteado, J. C. (org.).Justiça penal 6. São Paulo: Revista dos Tribunais, 1999.

17. Cf. Piovesan, F.; Guimarães, L. C. R. "Convenção sobre a eliminação de todas as formas de discriminação racial”. In: Direitos humanos: Construção da liberdade e da igualdade. São Paulo: Centro de Estudos, 1998.

18. A título de exemplo, cite-se a manifestação de uma importante organização do movimento negro: "a livre interpretação dos fatos pelo/a juiz/a é geralmente influenciada pelas teorias sociais que menosprezam a gravidade da violência racista - seja real ou simbólica - carnavalizando as relações raciais e alimentando o ideário da democracia racial”. Observatório Negro, Parecer do Projeto de Lei do Senado n.o 309 de 2004. Disponível em: http://www. leliagonzalez.org.br/material/ParecerPLS309_Observatorio-Negro-PE. pdf.

19. Os dados encontram-se expostos de maneira mais detalhada em Machado, M. "A legislação anti-racismo no Brasil e sua aplicação: um caso de insensibilidade do Judiciário?”. In: Revista Brasileira de Ciências Criminais, n. 74. 
Se tomarmos apenas as decisões em que havia sentença de mérito em primeira instância, vemos que houve no Tribunal mais condenações do que absolviçõos -25 condenações em relação a 16 absolvições. As condenações foram, em sua grande maioria, pelas variações do crime de injúria (simples ou qualificada, com ou sem causas de aumento de pena). Encontramos apenas uma condenação pelo crime de racismo do art. 20, caput, da Lei $\mathrm{n}^{\circ} 7.716 / 89$ e uma condenação pelo art. $4^{\circ}$ da mesma lei (negar ou obstar emprego).

No que diz respeito às decisões que se relacionavam apenas ao prosseguimento ou à extinção do processo, obtivemos um número superior de decisões pelo encerramento precoce do processo, em relação às decisões que determinam seu prosseguimento: são 38 decisões do primeiro tipo contra 29 do segundo. Esse nos pareceu ser o resultado problemático de nosso conjunto de casos e que, provavelmente, motiva a insatisfação em relação à aplicação da lei. Sua interpretação, contudo, não pode ser simplista.

A razão mais freqüente de tal desfecho é a discordância do Tribunal sobre a qualificação jurídica do caso - racismo, injúria simples ou injúria qualificada. A diferença de regimes de processamento desses crimes envolvidos nas divergências acerca da qualificação jurídica dada aos casos (ação penal de iniciativa pública ou privada) determina uma situação bastante problemática: toda vez que a desclassificação de racismo para injúria racial ocorrer após o prazo de 6 meses, terá já ocorrido a decadência do direito do ofendido de propor a ação penal por este. $\mathrm{Ou}$, ainda, se esta decisão for proferida deixando pouco tempo para que o ofendido viabilize a queixa crime, esse será um fator relevante para aumentar a probabilidade desse mesmo desfecho ou, ao menos, dificultar a preparação da ação a ser proposta.

A segunda causa mais relevante para a extinção precoce do processo foi a insuficiência de provas para embasar a acusação. Uma crítica a respeito da adequação ou não dessas decisões só seria possível a partir de uma análise qualitativa dos autos, considerando o princípio do livre convencimento do juiz. Em seguida, vêm os casos que foram encerrados antes ou durante a instrução em razão de inobservância de alguma formalidade requerida pela disciplina das ações penais de iniciativa privada. 
Analisando melhor a questão do ponto de vista interno do direito, é possível ao menos relativizar alguns dos diagnósticos que denunciam a impermeabilidade do judiciário às demandas da esfera pública. A interpretação dos magistrados pela qualificação do fato como injúria racial - embora tenha efeitos que possam ser avaliados como problemáticos do ponto de vista da resposta do sistema de justiça ao problema - é justificável do ponto de vista dogmático. Pode-se afirmar que o próprio arranjo da regulação no âmbito do direito positivo é que vem contribuindo em grande medida para tornar inócua a resposta do judiciário do ponto de vista da aplicação de sanção penal.

Sem abordar a discussão técnica acerca dos princípios de interpretação de leis penais e a interação entre normas processuais penais, podemos apontar que o fato de o judiciário, com freqüência, classificar os fatos como "injúria racial" e não "racismo" e isso ter como efeito, em boa parte dos processos, a sua extinção tem, por um lado, razões sistêmicas e não puramente culturais. Sem excluir as possíveis explicações, que apenas poderiam ser dadas mediante uma investigação empírica mais apurada, o que podemos por ora afirmar é que a dinâmica própria do sistema jurídico impede que tais resultados sejam explicados simplesmente como decorrência de um atavismo cultural ou da preferência dos agentes pela resolução informal dos conflitos, ou mesmo de um certo desejo de preservar o mito da "democracia racial". Nossa pesquisa mostrou que é importante considerar, nessa análise, os obstáculos institucionais que impedem o pleno acesso à via do direito.

Por outro lado, foi possível notar que os aplicadores da lei, se respondem às exigências formais e procedimentais impostas pelo próprio sistema judiciário, também não estão infensos, em alguma medida, aos processos de formação política da opinião e da vontade que têm lugar na esfera pública. E particularmente relevante o número crescente de casos que chegaram aos Tribunais nos últimos anos. ${ }^{20}$ Essas mudanças também coincidem com o

20. Trata-se de constatação meramente quantitativa a partir do levantamento do número de casos envolvendo racismo, discriminação racial ou injúria racial, entre 1998 e 2007, nos Tribunais de Justiça dos seguintes Estados: 
crescimento das mobilizações anti-racistas e da tematização pública do racismo. É verdade que para definir a correlação precisa entre esses dois conjuntos de processos - ou seja, com qual intensidade as mudanças observadas no judiciário são causadas pelas transformações políticas apontadas - faz-se necessário aprofundar as informações levantadas até o momento, especialmente quanto à porosidade dos juízes no que diz respeito aos argumentos por eles utilizados.

\section{Conclusões provisórias de um diagnóstico alternativo}

Considerando que os resultados aqui apresentados fazem parte de uma pesquisa mais ampla ainda em andamento, nossa conclusão não poderia ser senão provisória. Porém, apesar desse seu estatuto necessariamente preliminar, reunimos, ao longo do trabalho, indícios e evidências que fortalecem nossa hipótese mais geral, de acordo com a qual a efetividade do Estado de direito tem de ser compreendida segundo a dinâmica política colocada em ação por meio dos vínculos internos entre a esfera pública e as instituições do Estado.

Partimos da premissa geral segundo a qual o Estado de direito não pode ser entendido como a materialização sem fissuras de um conjunto abstrato de normas e procedimentos jurídicos. Implica antes um complexo conjunto de processos e procedimentos de interpretação, aplicação e justificação das leis, o qual procuramos reconstruir e estudar nos diferentes âmbitos e espaços em que se desenrola a dinâmica política dos conflitos. $\mathrm{O}$ primeiro âmbito apresentado, no qual se nota o cruzamento entre os processos informais de formação da opinião e da vontade e os espaços de deliberação formais, corresponde ao conjunto de demandas públicas por uma legislação penal anti-racismo. Da politização das diferenças culturais até uma pluralização de manifestações do anti-racismo, foi possível acompanhar um percurso de "mãodupla” entre as tematizações públicas e a criação e reformulação

São Paulo, Rio Grande do Sul, Mato Grosso do Sul, Roraima, Acre, Pernambuco, Rio de Janeiro, Paraíba e Bahia. 
da legislação. Se o legislativo reagiu, de alguma maneira, à discussão de questões ligadas ao racismo em suas várias fases, também os processos de criação e interpretação das leis geraram ondas de discussão do tema no âmbito da esfera pública. Nossa análise não poderia se restringir ao âmbito do legislativo, de modo que também uma compreensão adequada do judiciário é fundamental para avaliar a orientação da sociedade civil diante dos processos de institucionalização.

A análise interna sobre o funcionamento das instituições formais do Estado de direito aqui proposta permite alargar os diagnósticos sobre os diferentes tipos de entraves para a aplicação da legislação anti-racismo, bem como descrever os processos envolvidos no percurso de sua efetivação. Além disso, não pretendemos nos centrar unicamente no momento específico da aplicação por parte do juiz, mas considerar os diferentes modos de aplicação abertos no decorrer dos processos políticos. Para aqueles preocupados com os obstáculos e potenciais existentes nas lutas emancipatórias, é fundamental compreender o judiciário como um espaço a ser considerado pelas demandas sociais, ou seja, um espaço a ser politicamente disputado. O judiciário - que não apenas aplica as leis, mas também as interpreta no contexto de justificação de suas decisões - precisa ser percebido como uma importante esfera nas lutas por reconhecimento. A realização de pesquisa empírica sob tal perspectiva relaciona-se, portanto, com um dos problemas centrais para a nossa democracia: os déficits de publicidade sobre os processos de aplicação da lei, ou seja, de uma baixa compreensão pública de seus modos de funcionamento efetivos. Tais déficits se vinculam diretamente à inefetividade do Estado de direito, já que fragilizam ou decompõem as condições de reclamação judicial eficiente de normas e competências jurídicas feridas - tal como foi observado com respeito à decadência do direito de ação conta injúria racial. Para a superação desses déficits, é fundamental a consolidação de uma esfera pública nacional dedicada à veiculação, reflexão e crítica das rotinas de funcionamento das instituições judiciárias, o que no caso estudado se observou com muito menor intensidade que as deliberações acerca das etapas legislativas do processo político. 
Ainda que a partir de dados bastante preliminares, pudemos observar que o aumento do debate e das tematizações públicas em torno do racismo tende a impulsionar o Estado a incorporar as demandas sociais por uma legislação mais adequada. De outro lado, ao criticarmos o diagnóstico da "inefetividade" do direito no caso da legislação anti-racismo não pretendemos concluir seu oposto, a saber, a plena vigência de uma democracia racial no país. Ao contrário, a crítica a tal diagnóstico atinge principalmente seus pressupostos teórico-metodológicos, na medida em que impedem justamente uma melhor compreensão dos diferentes entraves e possibilidades para um combate mais efetivo ao racismo.

Em suma, interessa-nos, antes de tudo, criar condições para produzir criticamente um diagnóstico alternativo. As reivindicações e demandas políticas não se direcionam contra, mas para o Estado. Em outras palavras, não há negação do Estado de direito, mas, ao contrário, certa percepção de que os espaços institucionais de deliberação podem ampliar politicamente a interpretação bem como os modos efetivos de aplicação da legislação anti-racismo. O sistema jurídico não pode mais continuar a ser visto como um complexo de estruturas e práticas blindadas a intervenções críticas. Ele deve ser compreendido em seus diferentes momentos operacionais para que os entraves a sua plena democratização possam ser publicamente combatidos.

\section{Bibliografia}

ABREU, I. B. "O racismo e a jurisprudência do Egrégio Tribunal de Justiça do Estado de São Paulo”. In: PENTEADO, J. C. (org.). Justiça penal 6. São Paulo: Revista dos Tribunais, 1999.

BENHABIB, S. "Sobre um modelo deliberativo de legitimidade democrática”. In: MELO, R.; WERLE, D. L. (org).Democracia deliberativa. São Paulo: Esfera Pública, 2007.

BOHMAN, J. Public deliberation. Cambridge: MIT Press, 2000.

COSTA, S. As cores de Ercília: Esfera pública, democracia, configuraçôes pós-nacionais. Belo Horizonte: UFMG, 2002.

.; MELO, R.; SILVA, F. G. "Sociedad civil, Estado y derecho en América Latina: tres modelos interpretativos". In: ARAÚJO, K. 
(org). ¿ ¿Se acata pero no se cumple? Estudios sobre las normas en América Latina. Santiago: LOM, 2009.

FULLIN, C. S. "Direito e racismo: Observações sobre o alcance da legislação penal antidiscriminatória no Brasil". In: Revista da Faculdade de São Bernardo do Campo. 2000, Vol. 6.

GÜNTHER, K. "Qual conceito de pessoa de que necessita a teoria do discurso do direito? Reflexões sobre a conexão entre pessoa deliberativa, cidadão e pessoa de direito". In: MACHADO, M. R. A.; PÜSCHEL, F. P. (org). Teoria da responsabilidade no Estado democrático de direito: Textos de Klaus Günther. São Paulo: Saraiva, 2009.

HABERMAS, J. Faktizität und Geltung. Frankfurt/M: Suhrkamp, 1998.

MACHADO, M. "A legislação anti-racismo no Brasil e sua aplicação: um caso de insensibilidade do Judiciário?" In: Revista Brasileira de Ciências Criminais, n. ${ }^{\circ} 74$.

.; PÜSCHEL, F. P.; RODRIGUEZ, J. R. "The Juridification of Social Demands and the Application of Statutes: an Analysis of the Legal Treatment of Antiracism Social Demands in Brazil". In: FORDHAM Law Review, v. 77, 2009.

.; MELO, R.; SILVA, F. G. "The public sphere and the anti-racism legal protections in Brazil". In: Collection of Scientific Papers 2009. Riga: RSU, 2010.

MELO, R. "O uso público da razão como procedimento: Um contraste entre Rawls e Habermas”. In: doispontos, 5, 2008.

MÉNDEZ, J.; O'DONNELL, G.; PINHEIRO, P. S. (org). Democracia, violência e injustiça: O Não-Estado de direito na América Latina. São Paulo: Paz e Terra, 2000.

O'NEILL, O. Constructions of reason: Explorations of Kant's practical philosophy. Cambridge University Press, 1989

PETERS, B. Die Integration moderner Gesellschaften. Frankfurt/M: Suhrkamp, 1993.

"Recht, Staat und politische Öffentlichkeiten als Formen sozialer Selbstorganisation”. In: ___ Der Sinn Von Öffentlichkeit. Frankfurt/M: Suhrkamp, 2007.

PIOVESAN, F.; GUIMARÃES, L. C. R. "Convenção sobre a eliminação de todas as formas de discriminação racial”. In: Direitos humanos: Construção da liberdade e da igualdade. São Paulo: Centro de Estudos, 1998.

PRUDENTE, E. Preconceito racial e igualdade jurídica no Brasil. Campinas: Julex, 1989. 
RAWLS,J."A idéia de razão pública revisitada”.In:MELO, R.;WERLE, D. L. (org). Democracia deliberativa. São Paulo: Esfera Pública, 2007. SILVA, J. "A união dos homens de cor: Aspectos do movimento negro dos anos 40 e 50”. In: Estudos Afro-Asiáticos, 2003, 25. 